\title{
The Influence of Personal School Experience in Biology Classes on the Beliefs of Students in University Teacher Education
}

\author{
Christoph Schneider ${ }^{1}$, Ursula Pakzad ${ }^{2} \&$ Kisten Schlüter ${ }^{3}$ \\ ${ }^{1}$ Department of Childhood and Adolescent Education, University of Koblenz-Landau, Campus Landau, Germany \\ ${ }^{2}$ Institute for Biology and its Didactics, University of Siegen, Germany \\ ${ }^{3}$ Institute for Biology Education, University of Cologne, Germany \\ Correspondence: Christoph Schneider, University of Koblenz-Landau, Campus Landau, Department of Childhood \\ and Adolescent Education, August-Croissant-Strasse 5, 76829 Landau, Germany. Tel: 49-6341-2803-4141. \\ E-mail: schneider@uni-landau.de
}

\author{
Received: May 22, 2013 Accepted: June 13, 2013 Online Published: July 10, 2013 \\ doi:10.11114/jets.v1i2.146 \\ URL: http://dx.doi.org/10.11114/jets.v1i2.146
}

\begin{abstract}
Teachers' pedagogical beliefs are thought to play a prominent role in determining teacher behavior. In contrast to other professions, pedagogical beliefs of teachers and students in teacher education are widely influenced by personal experiences gained in school, which has been referred to as "apprenticeship of observation" (Lortie, 1975, p. 61).It can be assumed that student teachers already enter teacher education with a relatively firm set of beliefs about teaching. In our study, $\mathrm{N}=280$ student teachers in biology were asked to recall their own biology classes in school, employing a frame of reference provided by national standards for biology education in Germany. First, a factor analysis was conducted on students' responses. This analysis yielded four aspects (factors) according to which students' recall of their own biology classes in school is structured. Next, students were clustered into four biography types by means of their parameter values on the four factors. Students' beliefs about how biology should be taught are influenced by their biography. Our findings thus provide evidence for the influence of school biography on pedagogical beliefs in the field of biology education; however, this influence does not point in a uniform direction. When comparing university freshmen to more advanced student teachers, only one out of the four belief aspects was affected by students' progress in their university studies. A practical implication is that teacher educators are well-advised to incorporate their students' past experiences into the contents of their courses.
\end{abstract}

Keywords: biology education, pre-service, school biography, science education, teacher beliefs, teacher education

\section{Introduction}

"Teachers teach as they were taught, not as they were taught to teach" (e.g., Altman, 1983, p.24) is an old pedagogical notion, which underlines the significance of the impact of approximately 15,000 hours (Rutter, Maughan, Mortimore, \& Ouston, 1979) spent in school on later beliefs about teaching and learning. This "apprenticeship of observation" (Lortie, 1975, p. 61) may be quite unique to the professional field of schooling and teaching, and it is both likely and plausible that student teachers may be deeply influenced by what they themselves experienced in school, when entering teacher education at the university.

\subsection{Teacher Beliefs and Their Assessment}

Professional beliefs in general are seen as one of the most important determinants of professional behavior. In the educational sciences, teachers' pedagogical beliefs and their impact on teacher behavior in the classroom continues to be of central interest (e. g., Calderhead, 1996; Forgasz \& Leder, 2008; Pajares, 1992; Woolfolk Hoy, Davis, \& Pape, 2006). However, the beliefs construct overlaps in part with other psychological constructs such as conceptions, attitudes, subjective theories, opinions, and values are not very clear. Pajares (1992) thus characterized beliefs as a "messy construct".

In order to assess teachers' beliefs, a number of approaches have been applied throughout the past decades (see Calderhead, 1996; Fang, 1996). Generally, empirical research on beliefs is subject to the bandwidth-fidelity 
dilemma (Cronbach, 1990). This means that beliefs can, in principle, either be assessed with a holistic approach to gain information on the complex structure of an individual's set or system of beliefs, or with a reductionist approach to identify inter-individual differences with regard to a comparatively small set of "universal" beliefs.

In past research, teacher beliefs and their structure have often been evaluated and coded by employing qualitative methodology, such as interviews, video analysis, and stimulated recall techniques prompting teachers to reflect upon their classroom behavior. More recently, however, there has been a trend to assess teacher beliefs with standardized instruments, as pioneered by Peterson, Fennema, Carpenter, and Loef (1989). In particular, recent international large-scale teacher studies adopted this approach. In this way, in the OECD's Teaching and Learning International Survey TALIS (OECD 2009; 2010), teacher beliefs about teaching and learning were measured by means of two indices: constructivist beliefs about learning and instruction and direct transmission beliefs about learning and instruction. In a similar way, this distinction was made in the international TEDS-M study on mathematics teachers' competences (cf. Schmotz, Felbrich, \& Kaiser, 2010). It should be noted that in both studies constructivist and transmission beliefs were not seen as the two ends of a continuum, but as independent constructs.

\section{2 "Teachers Teach as They Were Taught, Not as They Were Taught to Teach" - the Influence of Biography on Teacher Beliefs}

The "age-old pedagogical dictum" (Altman, 1983, p. 24) that "teachers teach as they were taught..." has been cited or referred to by a number of authors (e. g., Cerreto \& Lee, 2004; Handal, 2003). It refers to what Lortie (1975, see also Zeichner \& Gore, 1990) termed "apprenticeship of observation" in the schoolteacher career, his rationale being that "The lessons taught by early yet persisting models rest on chance and personal preference; training in pedagogy does not seem to fundamentally alter earlier ideas about teaching" (Lortie, 1975, p. 79). Consequently, the very beginning of the learning history of a teacher does not take place upon entry into formal teacher education, but rather dates back to the own school biography. Teaching style and interaction patterns within a teacher are perceived as widely invariant by students (Seidel \& Prenzel, 2006). As students typically face a limited number of teachers within one domain in their school career, it seems reasonable to expect that the experiences gained by students within one domain are based on a quite coherent set of observations.

While this school of thought is plausible, relatively few studies have empirically investigated this hypothesis. Based on interviews of student teachers on a number of occasions in their first year in university, Calderhead and Robson (1991) concluded that students already enter university with a relatively firm set of beliefs. These beliefs, however, seem to be mainly shaped by personal memories of teachers as particularly "good" or "bad" examples, rather than by teaching methods experienced in school (Lortie, 1975; Bailey et al., 1996). But even if beliefs about teaching and learning acquired before entering university can be altered by teacher education, this does not necessarily imply that the altered beliefs are stable over time and, in consequence, transacted in later classroom teaching. Rather, progressive views acquired at university tend to vanish in favor of the former conservative ideas upon entering school service (see Handal, 2003; Hart, 2004; Zeichner and Tabachnik, 1981; 1985).

\subsection{Impact of Teachers' Beliefs on Classroom Teaching Behavior}

In a survey study in science education, Haney, Czerniak, and Lumpe (1996) examined the effect of beliefs about a number of reform strands (scientific inquiry, scientific knowledge, conditions for learning science, and applications in science learning) on the intentions to adapt own teaching behavior to these reform strands. For each strand, beliefs had a significant effect on intentions, suggesting that beliefs are, indeed, prerequisites to behavior. However, the assumption that teachers' beliefs have a direct effect on teaching behavior is subject to debate (see Forgasz \& Leder, 2008). Fang (1996) concluded that, in past research, the "relationship between beliefs and instructional practices varies from very consistent to very inconsistent" (p. 53).

When analyzing the structure of teacher beliefs and their consequences on teaching, it is a common approach to first distinguish types of teachers holding a characteristic set of beliefs and then examine whether these types differ in personality characteristics, behavior, or other dependent variables. Specifically focusing on biology education, Neuhaus and Vogt (2005) submitted in-service biology teachers to a cluster analysis on the basis of their attitudes towards teaching biology. They found three clusters, which they termed the pedagogically-innovative type, emphasizing the importance of social interaction in the classroom, the subject-matter-innovative type, stressing the importance of integrating everyday problems and experiences gained in experiments, and the subject-matter-conventional type, largely adhering to "traditional" teaching, mostly direct instruction. The latter type is widely congruent with teachers holding transmissive beliefs while the pedagogically-innovative type and the subject-matter-innovative type hold more constructivist views. In a similar design, Hartinger, Kleickmann, and Hawelke (2006) also identified clusters of teachers dominantly 
expressing constructivist or transmissive beliefs about teaching. Constructivist teachers gave pupils more room to develop ideas and students taught by these teachers were more motivated to learn.

In the reality of everyday classroom teaching, however, it cannot be automatically assumed that more constructivist beliefs of teachers influence teaching practices. In a study based on videotaped classroom observations of physics education in lower secondary schools, Seidel et al. (2008) could not find support for the thesis that constructivist teachers' classroom behavior displays more individual support for students or a higher degree of concern for accompanying the learning process. Furthermore, students' learning outcomes were not systematically affected by teacher beliefs. One explanation may be that numerous science teachers, largely regardless of their beliefs, do not feel adequately trained to implement constructivist teaching patterns in their lessons. Based on inconsistencies between science teachers' interviews and observational data, Brown and Melear (2006) concluded that "...potential science teachers may neither have the experience nor the competencies to teach inquiry" (p. 940), i.e. to teach in a constructivist way.

\subsection{The Competence Approach and the Output-Oriented Setting of Standards}

In recent years, the competence concept has become increasingly popular in helping to define educational goals. In brief, competences are thought to encompass more than knowledge or (latent) abilities but also include motivational, volitional and experience-based learning and problem solving aspects (cf. Weinert, 2001). Whether or not competences are actually acquired by the students is predominantly assessed by introducing or implementing standards which then may or may not be reached by the students. Formally introducing standards for school education in general, and for science education in particular, overall aims at clarifying goals. While systematizations like the German national standards (KMK, 2004; see below) and similar collections of competence domains (e.g., Haney, Czerniak, \& Lumpe 1996) provide a wide normative view on what school science education is expected to achieve, implementation of such standards in the classroom is a slow-moving process. Generally, standards strive to promote a more constructivist approach in science teaching (Woolfolk Hoy et al., 2006). There is some optimism that the introduction of standards may encourage teachers to re-think what they experienced in school as students.

The quite general concept of constructivist teaching may express itself in a number of approaches. In this sense, a number of studies refer to the effectiveness of teacher training on either competence-oriented and student-centered teaching strategies (Elster, 2009), or on the implementation of inquiry-based teaching strategies (e.g., Brown \& Melear, 2006; Liu, Lee, \& Lin, 2010; Lotter, Singer, \& Godley, 2009), or on the nature of science (NOS; e.g., Backhus \& Thompson, 2006; Donnelly \& Argyle, 2011; Lotter, Singer, \& Godley, 2009; Seung, Bryan, \& Butler, 2009), or on conceptual change orientation (Smith \& Neale, 1989). While in summary these studies (a) point at substantial deficits in science teachers' NOS understanding and knowledge of inquiry-based learning and (b) mainly reveal positive effects of training on teacher beliefs, it may still be a quantitative problem to access in-service teachers ${ }^{1}$. Aside from specifically designed interventions, however, there may a secular trend towards a more constructivist approach in science education. Comparing science teacher's beliefs from 1963 to contemporary conditions, Abrahams and Saglam (2010) found a relative shift towards a greater emphasis on practical work, use of authentic examples, and maintaining students' interest.

\subsection{How Biology Learning Should Be - German National Educational Standards in Biology Education}

Mediocre results of German samples of students in international large-scale comparisons have resulted in an increasing demand for standard-guided school education in a number of domains, including the natural sciences. For the natural sciences, German national educational standards encompass much of what is filed under scientific literacy in international literature. In detail, biology education should

- $\quad$ provide an experience-based approach to natural phenomena;

- $\quad$ pave the way to inquiry-based learning by means of formulating and testing hypotheses;

- employ science-specific language in arguing and reflecting results;

- incorporate the history of science;

- contribute to developing a rational and analytical world view; and

- provide a solid base of knowledge and strategies for the individual's latter orientation towards technology or

\footnotetext{
${ }^{1}$ Typically, teachers are only provided with an allowance of a couple of single days reserved for teacher training in a year. Furthermore, participation in teacher training is often on a voluntary basis. Thus, only a very small percentage of in-service teachers have access to adequate training.
} 
science-related professions (KMK, 2004, p. 6).

The implementation of standards in the classroom was the subject of specific in-service teacher training in Germany (Bayrhuber et al., 2007). An evaluation of this training (Elster, 2009) revealed positive effects on the attitudes and willingness to innovate with regard to own teaching methods in most participants. With a similar intention with regard to output-oriented teaching, the American Association for the Advancement of Science has issued "benchmarks", explicitly listing which learning goals students in different grades are expected to accomplish in science education (AAAS, 2009). Although the AAAS benchmarks are not limited to biology education and are structured in quite a different way than the German national standards, contents are very similar, thus underlining the importance of competence orientation in science learning.

\section{Methodology}

\subsection{Rationale of the Study and Research Questions}

As we expected that biology student teachers' beliefs on how biology education in school should be designed are to some extent shaped by experiences gained back in the "old school days", we first examined the empirical structure of these experiences. Regarding the German national standards on biology education (KMK, 2004) as a frame of reference for teacher behavior in the classroom, we used these standards for the assessment of experiences gained back in school. Since the categories inherent in the national standards were created on a normative basis, we did not adhere to the proposed categories, but rather submitted the single items of the national standards to an exploratory factor analysis. Thus, our first research question was: How many dimensions of perception of the individual student teachers' school experiences in biology lessons can be derived? Does the content of these dimensions overlap with more general transmissive vs. constructivist tendencies?

Next, we aimed at identifying groups of biology student teachers on the basis of their own school experiences. Similar to the research methodology of Neuhaus and Vogt (2005) and Seifried (2010), we submitted the student teachers in our sample to a cluster analysis on the basis of experience scales constructed on the basis of the factor analysis. Thus, our second research question was: How many types of experiences can be identified amongst the biology student teachers? In which ways do they differ? Which labels can be assigned to these types of experience?

Hypothesizing that experiences acquired during the individual school career also influence biology student teachers' beliefs about biology education, we then compared the beliefs held by these types of experience. In order to make (past) experiences and (future-oriented) beliefs comparable, we structured the beliefs according to the results of the exploratory factor analysis of experiences by applying the same arithmetic in calculating belief measures as in calculating experience scales. This procedure enabled us to answer our third research question: Do the types of experience differ with regard to beliefs about biology education? Do the profiles of the beliefs resemble the profiles of the experiences themselves? In other words, "do future biology teachers really strive to teach as they were taught?"

Last, it seemed reasonable to expect that future biology teachers' beliefs on biology education undergo some change in the course of university teacher education. Thus, our fourth research question was: Do the beliefs of university freshmen differ from the beliefs displayed by more advanced biology teacher education students? Does the change in beliefs as a result of teacher education generally point in a more constructivist direction?

\subsection{Research Instruments}

Our research instrument consisted of seven sections; the first four sections were directly linked to the German national standards for biology education competence domains (KMK, 2004). Three of the four domains of the national standards referred to procedural competences (inquiry, communication, and valuing and decision making), while one domain comprises biology content knowledge (for illustrations see Elster, 2009). The remaining three sections of our instrument referred to general pedagogical elements of teacher or pupil behavior that are not included in the biology-related standards, namely teaching methods, media, and social forms (whether the pupils work in the class as a whole, in groups, pairs, or on their own). In order to measure future biology teachers' individual (past) experiences in school, each item was answered from the perspective of "I, as a pupil, experienced this..." on a six-point Likert scale, ranging from very infrequently to very frequently ${ }^{2}$. The same answer format was employed to measure beliefs about how biology education should be designed. For this, the formulation was changed to "In school lessons, this should be applied...". In total, the instrument encompassed 52 items: Each had to be answered from these two perspectives.

\footnotetext{
${ }^{2}$ On these Likert-scales, only the two extreme positions carry labels. The ascending character of the scale is visualized graphically by a triangular gauge, as in a radio volume control.
} 


\subsection{Sample Characteristics}

Cross-sectional data were collected between the fall of 2007 and the fall of $2008^{3}$ at a university with a strong focus on teacher education in Germany. Participants were all university students $(N=280)$ enrolled in teacher education in the biology domain (referred to as student teachers). In the sample, $82.9 \%$ of the participants were female. Age ranged from 18 to 37 years with a mean of 21.5 years $(S D=3.1)$. Only $5 \%$ of the participants were older than 25 years.

Roughly half of the participants were university freshmen $\left(N_{\text {fresh }}=120 ; 42.9 \%\right)$, surveyed in the first few weeks after entering university studies. The more advanced students $\left(N_{\mathrm{adv}}=156 ; 55.7 \%\right)^{4}$ had on average completed 4.0 semesters of their program $(S D=1.8)$, i.e., two years of teachers studies in biology, and thus the majority had carried out practical phases in schools as a compulsory element of university teacher education. In Germany, student teachers have to decide on a school form career immediately upon entering university. In our sample, $N_{\text {prim }}$ $=86(30.7 \%)$ had selected a primary school teacher career ${ }^{5}$ (Grundschule); $N_{\text {lowsec }}=153(54.6 \%)$ were training to be lower-track secondary school teachers, teaching up to grade 10 (Haupt- und Realschule), and $N_{\text {highsec }}=39$ subjects $(13.9 \%)$ were training to be higher-track secondary teachers, teaching up to grade 13 (Gymnasium).

\subsection{Data Analysis Strategies}

The first research question, how many dimensions of perception can be derived from the experience item set, was treated by means of an exploratory factor analysis (principal axis method). As oblique factor rotation methods often lead to ambiguous interpretations of the dimensional structure (Johnson, 1998), we exclusively applied orthogonal varimax rotation. We then generated experience scales on the basis of the results of the factor analysis, by adding the scores of the respective items in order to calculate the internal consistencies of the scales and to inspect potential intercorrelations of the scale values. These experience scales were then employed as a basis for answering the second research question on how many distinct types of experiences made in school can be identified amongst the biology student teachers. To answer this question, we used hierarchical cluster analysis.

Our third research question was whether biology student teachers adhering to these types express different beliefs about biology education and whether these beliefs are in line with what they experienced in their own school career. To answer this question, we first calculated sum scores on the belief items using the same classification as when calculating the experience scales ${ }^{6}$. In order to evaluate whether future biology teachers "strive to teach as they were taught", we then compared the magnitude of the belief sets measures to the magnitude of the experience scales within each experience type. As there was no good theoretical reason to assume numerically equal magnitudes of beliefs and experiences, these comparisons were purely descriptive.

Another aspect of the third research question was answered along with the fourth research question, whether university freshmen and more advanced students differ in their beliefs about biology education by means of analyses of variance with the belief sets as separate dependent variables.

\section{Results}

\subsection{Results of the Exploratory Factor Analysis on Biology Student Teachers' Past School Experiences}

Before submitting the 52 items referring to own student experiences in school to a principal axis exploratory factor analysis, the data were first checked for adequacy. With a measure of sampling adequacy (MSA, also known as Kaiser-Meyer-Olkin criterion) of .86, the data proved to be appropriate for our purpose. Initially, 15 factors displayed an eigenvalue of greater than one, with a scree plot strongly pointing towards a four-factor solution. By means of a criterion defined to identify ambiguous items ${ }^{7}$, items were successively eliminated from the analysis. Elimination steps came to a halt when 31 items remained in the analysis, all meeting this criterion and the Fürntratt (1969) criterion $^{8}$. In choosing this strategy of analysis, we emphasized the need to find

\footnotetext{
${ }^{3}$ Time points of assessment vary as questionnaires were handed out and worked on in different biology courses

${ }^{4}$ Percentage of missing values was $1.4 \%$

${ }^{5}$ Of note, primary teacher education in Germany mandatorily encompasses studies in contextual domains. In this subsample, all teachers studied biology and are thus to be regarded as "full scale" biology teachers

${ }^{6}$ It is worth noting that we did not investigate the empirical structure of the belief items in the same way as we did when submitting the experience items to a factor analysis. It is thus possible that the sum scores do not exactly mirror the empirical structure of the belief items. Hence, we do not address the calculated measures as belief scales, but as belief sets. The anticipated benefit of this approach is that we can directly compare identical experience and belief contents.

${ }^{7}$ The primary loading of any item must be > |.40|; no secondary loading is allowed to exceed the |.40| threshold.

${ }^{8}$ The squared highest factor loading of an item must not be less than half the item's communality: $a^{2} / h^{2}>.50$.
} 
orthogonal, clearly interpretable factors. In the final four-factor solution on the remaining items, the rotated factors explained $35.9 \%$ of item variance. The rotated factor loading matrix is depicted in Table 1.

Table 1. Factor loadings for the Exploratory Factor Analysis with Varimax Rotation Encompassing 31 Items

Factor 1: Everyday- and Outlook-Oriented Teaching (EOOT) F1 F2 F3 F4

Scientific literature designed for children and youths is incorporated in the lessons .68

Articles from popular science journals are read

Experts (e. g., medical doctors, scientists, or nutritionists) are invited into the lessons or are visited at their $\mathbf{. 5 7}$ workplace

Much illustrative material (e.g., models, preparations or slides) is used

Whenever an issue is controversially discussed, students adopt perspectives of interest groups (affected persons, environmentalists, scientists, entrepreneurs...)

Everyday experiences are the 'opener' of any issue

Striking matters (e. g., from the daily press) are incorporated in the lessons

Scientific television broadcasts are incorporated in the lessons

Discussions on controversial topics (such as abortion, genetic engineering or cloning) are held, weighing up the pros and cons

Excursions into nature are made (e. g., for analyzing water quality or for species classification of trees or other plants)

Students may pursue own biological interests

The importance of environmental matters is stressed

Factor 2: Orientation on, Exposure and Comprehension of Biological Content Knowledge (OBCK)

Graphical charts (curves or bar graphs) are described and interpreted

Students apply a variety of biological approaches (exact observation, comparison, use of classification charts, work with microscope, or measurement instruments)

The teacher explains, demonstrates, and asks questions in the biology classroom

Note. Primary factor loadings are printed in boldface; Loadings below |.25| are not displayed; Item wordings have been translated from German for illustrative purposes. It is thus possible that these illustrations do not capture the full scope of the original item contents.

Item loadings on the four factors allow for a straightforward interpretation of the factors as dimensions of experiences acquired in school. Factor 1 consists of items referring to the incorporation of everyday experiences, expertise from the school context, and current controversial discussions on biology matters into the lessons. It is thus reasonable to label this factor as everyday-and outlook-oriented teaching (EOOT). Factor 2 assembles items with a variety of approaches, all aiming at the acquisition of biological content knowledge. We call this factor 
orientation on, exposure and comprehension of biological content knowledge (OBCK). As items emphasizing palpable forms of student action in the classroom make up factor 3, it is named learning through student action and practical experience (SAPE). Finally, factor 4 consists of items referring to the biology textbook and teacher explanations. It is termed textbook and teacher centered instruction (TTCI). In answer to our first research question, factors 1 and 3 clearly adhere to constructivist ideas, while factor 4 represents a transmissive view. Factor 2 is to some extent ambiguous, as both constructivist and transmissive elements are included in the items. All items on factor 2, however, are related to the acquisition of sound biological content knowledge.

Table 2. Internal Consistencies (Cronbach`s $\alpha$ ) and Scale Characteristics of the Scales Calculated on the Basis of Biographical Experience Item Loadings in the Four-Factor Solution

\begin{tabular}{llllllll}
\hline & & & & \multicolumn{5}{c}{ Intercorrelation With $\cdots$} \\
\hline Scale Name & No. of Items & $\alpha$ & Mean Sum Score of Scalee & Scale Variance & EOOT & OBCK & SAPE \\
\hline EOOT $^{\mathrm{a}}$ & 12 & .85 & 32.4 & 102.8 & & & \\
\hline OBCK $^{\mathrm{b}}$ & 10 & .84 & 41.0 & 80.8 & $.50^{* *}$ & & \\
\hline SAPE $^{\mathrm{c}}$ & 5 & .72 & 17.1 & 23.3 & $.42^{* *}$ & $.40^{* *}$ & \\
\hline TTCI $^{\mathrm{d}}$ & 4 & .64 & 20.6 & 9.6 & $-.19^{*}$ & -.08 & $-.13^{*}$ \\
\hline
\end{tabular}

Note. ${ }^{\mathrm{a}}$ EOOT: everyday and outlook-oriented teaching; ${ }^{\mathrm{b}} \mathrm{OBCK}$ : orientation on, exposure and comprehension of biological content knowledge; ${ }^{\mathrm{c}} \mathrm{SAPE}$ : learning through student action and practical experience; ${ }^{\mathrm{d}}$ TTCI: textbook and teacher centered instruction; ecorresponding to the number of items and the original scale range: $1=$ very infrequently, $6=$ very frequently; $* *$ $\mathrm{p}<.01, * \mathrm{p}<.05 ; \mathrm{N}=279$.

Next, scales on the dimensions of school experiences were calculated by adding the item raw scores for the items of each factor and then inspected for internal consistencies (Cronbach's $\alpha$ ) and intercorrelations. Results are presented in Table 2. Consistencies (Cronbach's $\alpha$ ) of the four scales are acceptable to good. As displayed in Table 2, the EOOT, OBCK, and SAPE scales are positively correlated $(.40 \leq r \leq .50)$, while TTCI is mildly negatively correlated with all other scales $(-.08 \leq r \leq-.19)$.

\subsection{Results of the Cluster Analysis for Identifying Types of Past School Experiences}

Next, we strived to answer our second research question: How many types of school experience can be identified in our sample of biology student teachers, by means of hierarchical cluster analysis? The input variables for the clustering of cases were the four scales described above. Squared Euclidian distances were used. As the Ward clustering algorithm is known to produce biased results in the presence of outliers in the data, we first submitted the subjects in our sample to a single linkage cluster analysis. Visually inspecting the dendrogram documenting the fusion history of the single linkage algorithm, we identified 18 outliers (6.5\%), which were excluded from subsequent analyses. All further analyses thus referred to the remaining 261 subjects $^{9}$. In the subsequent Ward cluster analysis, the elbow criterion ${ }^{10}$ pointed at a two-cluster solution.

There were two strong arguments, however, against deciding on two clusters: First, the two-cluster solution failed to meet the variance criterion ${ }^{11}$, as the variance of the TTCI instruction scale in one of the two clusters was greater than the variance of this scale in the entire sample, pointing at non-homogenous clusters. Second, inspection of the scale means in the two clusters revealed that the solution would be trivial, as cluster one was characterized by a high score on the TTCI scale and comparatively high scores on the remaining scales (EOOT, OBCK, and SAPE), while subjects in cluster two scored equally high on TTCI, but lower than subjects in cluster one on all other scales. Thus, the two-cluster solution would not have allowed discrimination between subjects' TTCI experiences. Both the three-cluster and the four-cluster solution met the variance criterion. In the three-cluster solution, the first three clusters of the four-cluster solution appeared in an almost identical manner. However, the very interesting fourth cluster (the experience-oriented, diversified type of biographical experiences in biology lessons) was missing. As this type of instruction comes closest to state-of-the-art biology learning, we preferred the four-cluster solution to the more trivial three-cluster solution, and thus conducted subsequent analyses based on the four-cluster solution.

In order to evaluate the stability of the four-cluster solution obtained by the Ward algorithm, a partitioning cluster analysis (k-means) with a set number of four clusters was calculated, using the Ward cluster centers as

\footnotetext{
${ }^{9}$ One more subject had to be excluded from the analysis due to missing data on the scale means.

${ }^{10}$ This criterion checks for an elbow in the development of the sum of squared errors in the fusion history.

${ }^{11}$ The variance of any clustering variable in any cluster must not exceed the variance of this variable in the entire sample.
} 
starting values. There was a clear concordance of cluster memberships of the cases across the mathematically diverging clustering algorithms. Of all 261 cases in the analysis, 32 cases $(12.2 \%)$ belonged to a different cluster in the k-means analysis than in the Ward analysis. As a measure for concordance, Cohen's $x$ was calculated. Cohen's $x$ was .83 , pointing at an "almost perfect" (Landis \& Koch, 1977, p. 165) concordance. In answer to our second research question on how many types of biographical experience can be identified, we were able to distinguish four types by means of cluster analysis.

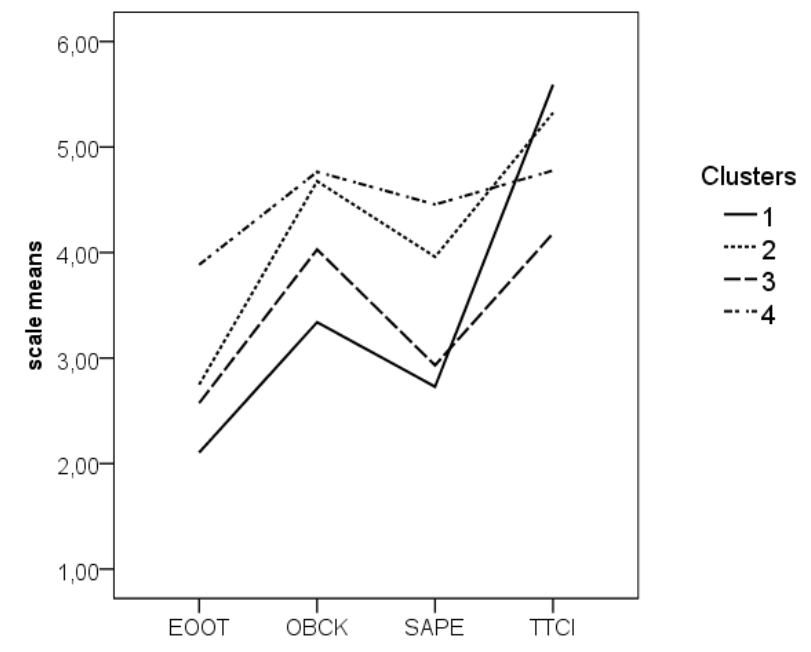

Figure 1. Experience Scale Means for the Four-Cluster Solution in the Ward Analysis With Reference to the Original Scale Range (1-6); for Abbreviations See Table 2.

Cluster profiles of the four-cluster solution of the Ward analysis are depicted in Figure $1^{12}$. Biographical experiences of cases in the first cluster are characterized by a strong focus on TTCI, while all other aspects of teaching (EOOT, OBCK, and SAPE) are, in relation, neglected. It seems reasonable to name this cluster as the single-edge teacher and textbook focused experience type (type 1). This cluster contains 99 cases (37.9\%). In the second cluster, emphasis on TTCI is almost equally strong, but in contrast to the first cluster OBCK is high and SAPE is well above the grand mean. This type, encompassing 94 cases (36.0\%) can in consequence be labeled the content knowledge, student action and teacher-oriented type of experience (type 2).

Scale means of the third cluster fail to form an accentuated profile. Still, OBCK and TTCI are rated higher than EOOT and SAPE. In this cluster, named the indifferent type of biographical experience (type 3), 32 cases (12.3\%) are to be found. The fourth cluster, with 36 cases (13.8\%), shows the most interesting profile. In contrast to all other clusters, EOOT is high. Remarkably, the high EOOT is not accompanied by a neglect of all other scales. Biographical school experiences of cases in this cluster are thus characterized by a high emphasis on incorporating everyday experiences and outlooks into biology lessons, but not at the expense of the other aspects. It seems adequate to name this cluster the experience-oriented, diversified type (type 4).

\subsection{Results of the Comparisons between Types of Biology Student Teachers' Beliefs Sets}

We calculated sum scores across the belief items adhering to one set of beliefs, the sets being defined by the empirical experience scale structure as described above. The respective scores were labeled EOOT beliefs, OBCK beliefs, SAPE beliefs, and TTCI beliefs. Although the structure of beliefs was not investigated empirically $^{13}$, the items within the sets proved to be satisfyingly consistent, with Cronbach's $\alpha$ ranging between .64 and .85 . Also, the pattern of intercorrelations amongst the belief sets was relatively similar to the pattern amongst experience scales (Table 2). For each of the four types of experience, as identified by the cluster analysis, the magnitude of the experience scales and belief sets were compared on a descriptive level. These magnitudes are contrasted in Figure 2.

\footnotetext{
${ }^{12}$ As a graphical display of cluster profiles does not provide information on the variance of scales means and thus on the heterogeneity of cases within the clusters, it must explicitly be pointed out that the maximum standard deviation of any scale mean in any cluster is $S D_{\max }=0.72\left(S D_{\text {mean }}=0.56\right.$; referring to the scale range of 1-6). Thereby, all clusters are relatively homogenous with respect to the clustering variables.

${ }^{13}$ See footnote in the Methodology section.
} 


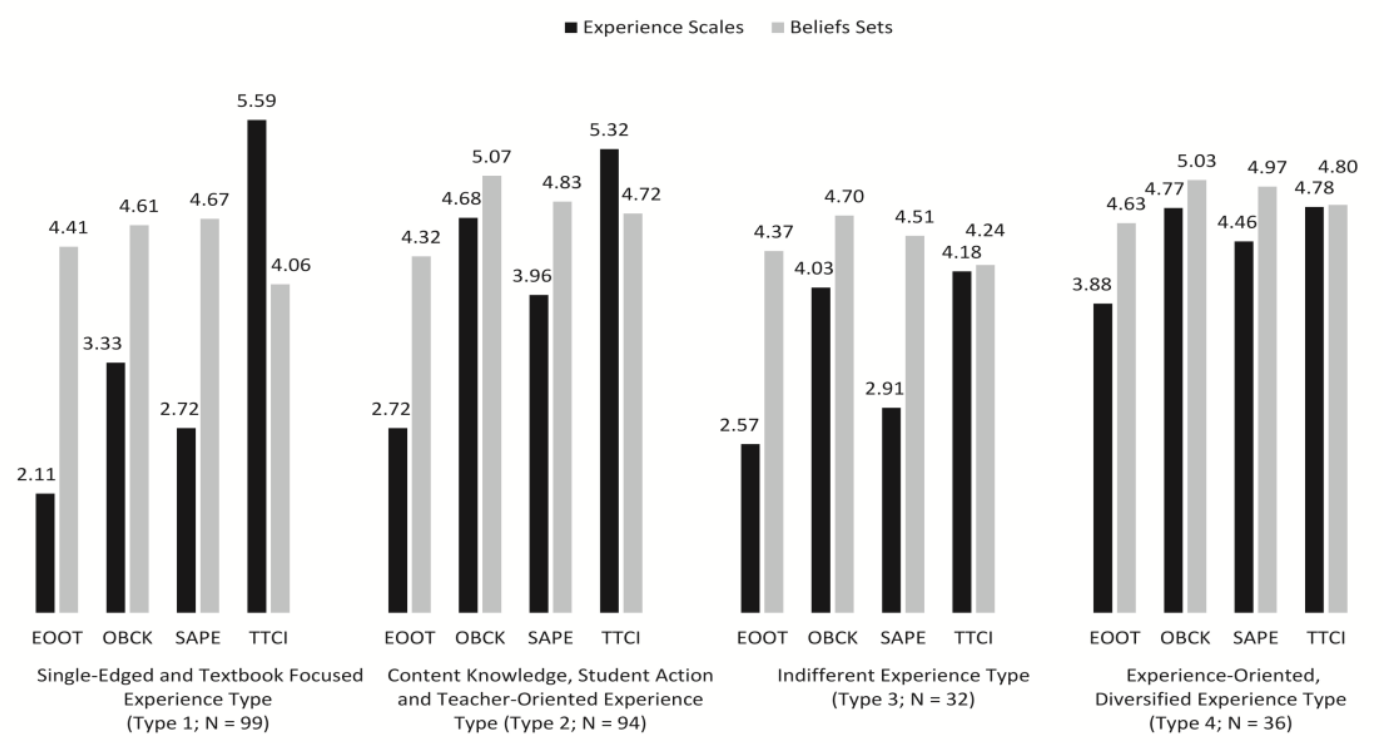

Figure 2. Magnitudes of Experiences and Beliefs' for the Four Types of Biographical Experiences With Reference to the Original Scale Range (1-6); For Abbreviations see Table 2.

For the single-edge teacher and textbook focused experience type (type 1), the magnitude of all beliefs about biology education, except the TCCI belief considerably exceeds the magnitude of the experiences with the most prominent differences for EOOT and SAPE. TTCI, in turn, is lower in the belief than in the experience, pointing at "too much" textbook-and-teacher orientation during past school experiences. In the content knowledge, student action and teacher-oriented experience type (type 2), EOOT displays the greatest difference between experiences and beliefs, followed by SAPE. The same pattern holds true for the indifferent experience type (type 3 ), while the difference between SAPE experiences and beliefs is much larger for this type. In contrast to all other experience types, experiences and beliefs do not diverge prominently for the experience-oriented, diversified type (type 4). For this type, past experiences acquired in the own school career and beliefs about biology education are widely congruent. Thus, the question whether "teachers strive to teach as they were taught" cannot be answered in a universal way. In our data, the dictum only holds true for the experience-oriented, diversified type (type 4), which makes up only $14 \%$ of the cases in our sample. For all other experience types identified by our analysis, the question has to be answered negatively, most prominently so for the single-edge teacher and textbook focused experience type.

\subsection{Influences of Biographical School Experiences and Progress in Teacher Studies on Belief Sets}

Analyses of variance were conducted on our third and fourth research questions simultaneously. In these analyses with the four belief sets as dependent measures, we elucidated whether variation in the belief set measures was due to biographical experience (contrasting the four types of experience), the progress-in-studies (contrasting biology education university freshmen and advanced students), and possibly an interaction of both. Descriptive statistics for all cells are given in Table 3.

Table 3. Beliefs about Biology Education: Descriptive Statistics for the Four Experience Types and for Progress-in-Studies

\begin{tabular}{|c|c|c|c|c|c|c|c|c|}
\hline \multirow{2}{*}{$\begin{array}{l}\text { Progress-in-Studies } \\
\text { Experience Types }\end{array}$} & \multicolumn{4}{|c|}{ University Freshmen } & \multicolumn{4}{|c|}{ Advanced Students } \\
\hline & Type 1 & Type 2 & Type 3 & Type 4 & Type 1 & Type 2 & Type 3 & Тур \\
\hline \multirow[t]{2}{*}{$N$} & 24 & 54 & 18 & 17 & 74 & 39 & 13 & 18 \\
\hline & $M( \pm S D)$ & $M( \pm$ & $M( \pm S D)$ & $M( \pm S D)$ & $M( \pm S D)$ & $M( \pm S D)$ & $M( \pm S D)$ & $M( \pm S D)$ \\
\hline EOC & $4.20(.94)$ & $4.31(.62)$ & $4.31(.57)$ & $4.32(.68)$ & $4.47(.72)$ & $4.38(.67)$ & $4.38(.41)$ & $4.73(.57)$ \\
\hline OBCK $^{\mathrm{b}}$ Beliefs & $4.67(.63)$ & $5.12(.37)$ & $4.75(.41)$ & $4.89(.55)$ & $4.60(.52)$ & $5.01(.48)$ & $4.59(.46)$ & $5.13(.49)$ \\
\hline SAPE $^{\mathrm{c}}$ Beliefs & $4.63(.64)$ & $4.82(.47)$ & $4.49(.38)$ & $5.08(.63)$ & $4.66(.58)$ & $4.81(.51)$ & $4.51(.77)$ & $4.82(.56)$ \\
\hline TTCI $^{\mathrm{d}}$ Beliefs & $4.60(.81)$ & $4.89(.59)$ & $4.43(.66)$ & $5.03(.48)$ & $3.91(.81)$ & $4.46(.93)$ & $3.98(.85)$ & $4.53(.62)$ \\
\hline
\end{tabular}

Note. Overall $\mathrm{N}=257$; aEOOT: everyday and outlook-oriented teaching; bOBCK: orientation on, exposure and comprehension of biological content knowledge; cSAPE: learning through student action and practical experience; dTTCI: textbook and teacher centered instruction: Means and standard deviations refer to the original scale range (1-6); Experience Type 1: 'single-edge teacher and textbook focused'; Type 2: 'content knowledge, student action and teacher-oriented'; Type 3: 'indifferent'; Type 4: 'experience-oriented, diversified'. 
For the EOOT belief set, the magnitude of differences did not reach statistical significance on any factor. For the OBCK belief set, there was a significant $(F(3,253)=12.97, p<.001)$ biography effect, along with a "medium" to "high" effect (part. $\eta^{2}=.135$ ) size following the Cohen (1988) classification. Post-hoc analyses (Scheffé tests, judging by $p<.05$ ) revealed that the single-edge teacher and textbook focused experience type's (type 1) OBCK beliefs were lower than those of the content knowledge, student action and teacher-oriented and experience-oriented, diversified types (types 2 and 4). Also, OBCK beliefs of the indifferent type (type 3) were lower than for the content knowledge, student action and teacher-oriented type (type 2).

For the SAPE belief set, there was a significant $\left(F(3,253)=4.90, p=.003, \eta_{\mathrm{p}}{ }^{2}=.056\right)$ biography effect. Post-hoc analysis revealed that the indifferent type's (type 3) SAPE beliefs were lower than for types 2 and 4. Another significant $\left(F(3,253)=6.93, p<.001, \eta_{\mathrm{p}}{ }^{2}=.077\right)$ biography effect was found for the TTCI belief. Most interestingly, in the post hoc analysis, the single-edge teacher and textbook focused experience type's (type 1) TTCI belief was found to be lower than for types 2 and 4 . Also the indifferent type (type 3 ) held a lower TTCI belief than the content knowledge, student action and teacher-oriented type (type 2). Furthermore, TTCI belief was the only dependent variable in our analysis with a significant progress-in-studies effect $(F(1,255)=21.16, p$ $<.001, \eta_{\mathrm{p}}{ }^{2}=.078$ ). Advanced students scored significantly lower than university freshmen only in the TTCI belief. All other effects including all interactions failed to reach statistical significance in the ANOVAs.

\section{Discussion}

\subsection{Summary and Interpretation of Findings}

To answer our first research question, factor analysis enabled us to derive four broad dimensions of the perception of biographical school experiences, namely everyday and outlook-oriented teaching (EOOT), orientation on, exposure and comprehension of biological content knowledge (OBCK), learning through student action and practical experience (SAPE), and textbook and teacher centered instruction (TTCI). With respect to the constructivist vs. transmissive categories of teaching, EOOT and SAPE clearly encompass constructivist elements, while TTCI is widely congruent with transmissive teaching. Next, a cluster analysis on the subjects in our sample identified four types of experience for the own school biography in biology education. These types were labeled single-edge teacher and textbook focused (type 1; $37.9 \%$ of all cases), content knowledge, student action and teacher-oriented (type 2; $36.0 \%$ ), indifferent (type 3; $12.3 \%$ ), and experience-oriented, diversified (type $4 ; 13.8 \%$ ) type.

Both the single-edge teacher and textbook focused and the indifferent type (types 1 and 3) express transmissive experiences acquired in the biology classroom back in school. Of note, experiences reported by the single-edge teacher and textbook focused type (type 1) do not place a strong focus on different methods of acquisition of content knowledge. As school experiences incorporating everyday problems and outlooks beyond the scope of the lesson itself are exclusively acquired by the experience-oriented, diversified type (type 4), cases in this cluster are possibly the only subjects in our sample who have experienced a constructivist approach to teaching. Finally, the content knowledge, student action and teacher-oriented type (type 2) of biographical experiences includes a relative emphasis on "hands-on" learning through student action. As such, these experiences include at least one aspect of constructivist teaching.

From a different perspective, our results also back the findings of Seidel and Prenzel (2006) obtained from video observations of physics classes. First, according to Seidel and Prenzel, teaching patterns tend to be quite stable within teachers but do vary between teachers, pointing at relatively firm belief sets within teachers. This is largely in line with our findings of clearly distinguishable clusters of experiences acquired in school. Second, traditional teaching methods based on direct instruction outweighed more constructivist teaching patterns such as making constructive use of student contributions in German physics classrooms (Seidel \& Prenzel, 2006). As, according to our data, TTCI is highest in all types of experience in absolute terms, it (still) appears to be an inevitable element in the biology classroom. Thus, constructivist teaching patterns cannot be expected to replace transmissive patterns, but at best accompany transmissive teaching.

The descriptive comparison of the profiles of experiences and beliefs across the types of experience clusters is depicted in Figure 2. Differences in beliefs between the clusters indicate that the biographical school experience of biology student teachers does indeed affect beliefs about biology education. The impact is not universal, however, but ranges from high concordance between experiences and beliefs to quite the contrary. The "teachers want to teach as they were taught" dictum only seems to fully hold true for the few student teachers of the experience-oriented, diversified type, who actually experienced biology classes characterized by everyday and outlook-orientation, as well as learning through student action and experience. Discrepancies between experiences and beliefs are smaller in the clusters of students having experienced rather constructivist teaching 
and greater in the clusters of those having experienced transmissive teaching. Nonetheless, students of all clusters express high TTCI beliefs in absolute terms. Direct instruction and the use of the textbook are thus regarded as an inevitable element of biology education.

Analyses of variance on the belief sets as separate dependent variables address the research questions as to whether biographical experience and/or progress-in-studies have an influence on the beliefs of biology student teachers. It should be noted that neither the biographical experience nor the progress-in-studies factor has a significant impact on EOOT beliefs. As the EOOT belief is moderately high in all experience types, this may be interpreted in a "few had it, but all want it" sense. OBCK beliefs are influenced by biographical experience, but not by progress-in-studies. As revealed by post-hoc comparisons, students in the more transmission-dominated clusters (types 1 and 3 ) hold lower OBCK beliefs than those with more constructivist school experiences (types 2 and 4). This suggests that dominating experiences of direct instruction do not imply a strong belief about the relative importance of the acquisition of biological content knowledge. On the contrary, those having experienced rather constructivist biology education value the acquisition of content knowledge higher by trend than those with transmission experiences. Biographical experience, but not progress-in-studies, also has a significant impact on SAPE beliefs. In particular students of the indifferent type (type 3) express relatively low SAPE beliefs in contrast to the clusters with more constructivist experiences (types 2 and 4). This may possibly be due to the low SAPE experiences gained by students of type 3 and may indicate that these students are less able to express beliefs about something they rarely experienced themselves.

Finally, biographical experience also has a significant influence on TTCI beliefs. Students of the single-edge teacher and textbook focused experience type (type 1) express the lowest TCCI beliefs of all clusters. This may be interpreted as a reactance effect (cf. Brehm \& Brehm, 1981) in objection to excessive direct instruction, combined with the intention to apply teaching approaches very different from the student teachers' individual school experiences. We are able to additionally find a significant progress-in-studies effect only for TTCI beliefs, with advanced students holding lower TTCI beliefs than university freshmen. With some caution, this may be interpreted as a relative immunity of belief sets against teacher education, except for the growing insight that TTCI alone is not the best possible instruction approach. Furthermore, the absence of any significant biography $\mathrm{x}$ progress-in-studies interaction suggests that the magnitude of the impact of past school experiences on beliefs about biology education is not substantially altered in the course of biology teacher education.

\subsection{Limitations of the Study and Desiderata for Further Research}

One apparent limitation is that our sample consisted of students in biology teacher education in one university at one point of time. Hence, our findings may not claim overall representativity for the population of biology student teachers Furthermore, our design does allow any causal interpretations, as would have been possible in analyzing longitudinal data. In this context, it must also be pointed out that our study is solely based on self-reports of experiences and beliefs. Whether or not these beliefs later translate into teaching behavior cannot be inferred from our data. It is thus necessary to corroborate our findings by analyzing data collected in (a) multi-centered, possibly international, and (b) longitudinal designs, including the assessment of behavior data on teaching.

\subsection{Practical Implications}

Our results demonstrate that biographical school experience has differential influences on beliefs about biology teaching and learning. As biographical experience has an influence on three out of four belief sets, and progress-in-teacher-studies has an impact on only one out of four sets, it can be cautiously supposed that past biographical school experiences are of a higher, or at least equal, relative importance to teacher education students than lectures in biology teacher education. In consequence, teacher educators should be even more aware that the possible impact of their lectures and courses is somewhat limited and cannot necessarily outweigh the impact of other determinants of their students' beliefs.

Only a small proportion of students, namely those who have experienced biology classes prominently incorporating everyday orientation and student action, holds a set of beliefs that is quite "in line" with past experience. It is likely that these students are able to report good practice examples from their school biographies and reflect upon what made these "former" teachers so successful. Thinking ahead, this may be very helpful in formulating and validating hypotheses on how these good practice teaching patterns experienced in school can be adopted in later teaching action. The great majority of students, however, expresses beliefs on how biology education should be that are quite different from school experiences, most explicitly so when their own school experience was mainly textbook and teacher-centered. These students can, in turn, be expected to report bad practice examples from their school history and reflect upon the decisive shortcomings in the way they 
experienced biology lessons from a student perspective. Be it in a positive or in a negative sense, both groups of biology students teachers are most certainly able to contribute to, or even actively participate in, the conception of university courses on "good" teaching patterns in the biology classroom. Our argument is that students already enter university laden with a huge body of experience on teaching and learning, and are able to distinguish between favorable and disadvantageous teaching patterns. It would thus be a waste of effort and thought, if not altogether counterproductive, to simply ignore this significant body of knowledge and its possible effect on enabling students to develop a "biology teacher identity" in university courses.

\section{References}

AAAS (American Association for the Advancement of Science). (2009). Benchmarks online. Retrieved from http://www.project2061.org/publications/bsl/online/index.php

Abrahams, I., \& Saglam, M. (2010). A Study of Teachers' View on Practical Work in Secondary Schools in England and Wales. International Journal of Science Education, 32(6), 753-768. http://dx.doi.org/10.1080/09500630902777410

Altman, H. B. (1983). Training foreign language teachers for learner-centered instruction: deep Structures, surface structures, and transformation. In J. E. Alatis, H. Stern, \& P. Strevens (Eds.), Georgetown University Round Table on Languages and Linguistics. Applied linguistics and the preparation of second language teachers: toward a rationale (pp. 19-25). Washington, DC US: Georgetown University Press.

Backhus, D. A., \& Thompson, K. W. (2006). Addressing the Nature of Science in Presercice Science Teacher Preparation Programs: Science Educator Perceptions. Journal of Science Teacher Education, 17, 65-81. http://dx.doi.org/10.1007/s10972-006-9012-9

Bailey, K. M., Bergthold, B., Braunstein, B., Jagodzinski Fleischmann, N., Holbrook, M. P., Tuman, J. ... (1996). The language learner's autobiography: Examining the "apprenticeship of observation". In D. J. Freeman \& J. C. Richards (Eds.), Teacher Learning in Language Teaching (pp. 11-29). Cambridge: Cambridge University Press.

Bayrhuber, H., Bögeholz, S., Elster, D., Hamman, M., Hössle, C., Lücken, M. ... (2007). Biologie im Kontext: Ein Programm zur Kompetenzförderung durch Kontextorientierung im Biologieunterricht und zur Unterstützung von Lehrerprofessionalisierung. Mathematischer und Naturwissenschaftlicher Unterricht, 60(5), 282-286.

Brehm, S. S., \& Brehm, J. W. (1981). Psychological reactance: A theory of freedom and control. New York: Academic Press.

Brown, S. L., \& Melear, C. T. (2006). Investigation of Secondary Science Teachers' Beliefs and Practices after Authentic Inquiry-Based Experiences. Journal of Research in Science Teaching, 43(9), 938-962. http://dx.doi.org/10.1002/tea.20110

Calderhead, J. (1996). Teachers: Beliefs and Knowledge. In D. C. Berliner \& R. C. Calfee (Eds.), Handbook of educational psychology (pp. 709-725). New York: Simon \& Schuster Macmillan.

Calderhead, J., \& Robson, M. (1991). Images of teaching: Student teachers' early conceptions of classroom practice. Teaching \& Teacher Education, 7(1), 1-8.

Cerreto, F. A., \& Lee, J. (2004). Finding Common Ground for Content and Technology: A Model for Course Development. Journal of College Teaching \& Learning, 1(4), 71-76.

Cohen, J. (1988). Statistical power analysis for the behavioral sciences (2. ed., 9. printing.). Hillsdale, N.J: Lawrence Erlbaum.

Cronbach, L. J. (1990). Essentials of psychological testing (5th ed.). New York: Harper Collins Publ.

Donnelly, L. A., \& Argyle, S. (2011). Teachers' Willingness to Adopt Nature of Science Activities Following a Physical Science Professional Development. Journal of Science Teacher Education, 22, 475-490. http://dx.doi.org/10.1007/s10972-011-9249-9

Elster, D. (2009). Biology in Context: teacher's professional development in learning communities. Journal of Biological Education, 43(2), 53-61.

Fang, Z. (1996). A review of research on teacher beliefs and practices. Educational Research, 38(1), 47-65.

Forgasz, H., \& Leder, G. C. (2008). Beliefs about Mathematics and Mathematics Teaching. In P. Sullivan \& T. Wood (Eds.), The International Handbook of Mathematics Teacher Education: Vol. 1. Knowledge and beliefs in mathematics teaching and teaching development (pp. 173-192). Rotterdam: Sense Publishers. 
Fürntratt, E. (1969). Zur Bestimmung der Anzahl interpretierbarer gemeinsamer Faktoren. Diagnostica, 15, $62-76$.

Handal, B. (2003). Teachers' Mathematical Beliefs: A Review. The Mathematics Educator, 13(2), 47-57.

Haney, J. J., Czerniak, C. M., \& Lumpe, A. T. (1996). Teacher Beliefs and Intentions Regarding the Implementation of Science Education Reform Strands. Journal of Research in Science Teaching, 33(9), 971-993.

Hart, L. C. (2004). Beliefs and Perspectives of First-Year, Alternative Preparation, Elementary Teachers in Urban Classrooms. School Science and Mathematics, 104(2), 79-88.

Hartinger, A., Kleickmann, T., \& Hawelka, B. (2006). Der Einfluss von Lehrervorstellungen zum Lernen und Lehren auf die Gestaltung des Unterrichts und auf motivationale Schülervariablen [The influence of teachers' conceptions of teaching and learning on the design of lessons and on motivational pupil variables]. Zeitschrift für Erziehungswissenschaft, 9(1), 110-126.

Johnson, D. E. (1998). Métodos multivariados aplicados al análisis de datos. México, D. F.: International Thomson Editores.

KMK (Kultusministerkonferenz). (2004). Bildungsstandards im Fach Biologie für den Mittleren Schulabschluss: Beschluss vom 16.12.2004. München, Neuwied: Luchterhand. Retrieved from http://www.kmk.org/fileadmin/veroeffentlichungen_beschluesse/2004/2004_12_16-Bildungsstandards-Biol ogie.pdf

Landis, J. R., \& Koch, G. G. (1977). The Measurement of Observer Agreement for Categorical Data. Biometrics, 33(1), 159-174.

Liu, O. L., Lee, H.-S., \& Linn, M. C. (2010). Multifaceted Assessment of Inquiry-Based Science Learning. Educational Assessment, 15, 69-86. http://dx.doi.org/10.1080/10627197.2010.491067

Lortie, D. C. (1975). Schoolteacher: A Sociological Study. Chicago and London: The University of Chicago Press.

Lotter, C., Singer, J., \& Godley, J. (2009). The Influence of Repeated Teaching and Reflection on Preservice Teachers' Views of Inquiry and Nature of Science. Journal of Science Teacher Education, $20,553-582$. http://dx.doi.org/10.1007/s10972-009-9144-9

Neuhaus, B., \& Vogt, H. (2005). Dimensionen zur Beschreibung verschiedener Biologielehrertypen auf Grundlage ihrer Einstellung zum Biologieunterricht. Zeitschrift für Didaktik der Naturwissenschaft, 11, 73-84.

OECD (2009). Creating Effective Teaching and Learning Environments: First Results from TALIS (Teaching and Learning International Survey). $\quad$ Paris. Retrieved from http://www.sourceoecd.org/education/9789264056053

OECD (2010). TALIS 2008 Technical Report. Paris. Retrieved from http://www.sourceoecd.org/education/9789264079854

Pajares, M. F. (1992). Teachers' Beliefs and Educational Research: Cleaning Up a Messy Construct. Review of Educational Research, 62(3), 307-332.

Peterson, P. L., Fennema, E., Carpenter, T. P., \& Loef, M. (1989). Teacher's Pedagogical Content Beliefs in Mathematics. Cognition and Instruction, 6(1), 1-40.

Rutter, M., Maughan, B., Mortimore, P., \& Ouston, J. (1979). Fifteen thousand Hours. Secondary Schools and their effect on children. London: Open Books Publishing Limited.

Schmotz, C., Felbrich, A., \& Kaiser, G. (2010). Überzeugungen angehender Mathematiklehrkräfte für die Sekundarstufe I im internationalen Vergleich. In S. Blömeke, G. Kaiser, \& R. Lehmann (Eds.), TEDS-M 2008. Professionelle Kompetenz und Lerngelegenheiten angehender Mathematiklehrkräfte für die Sekundarstufe I im internationalen Vergleich (pp. 279-305). Münster: Waxmann.

Seidel, T., \& Prenzel, M. (2006). Stability of Teaching Patterns in Physics Instruction: Findings from a Video Study. Learning and Instruction, 16, 228-240. http://dx.doi.org/10.1016/j.learninstruc.2006.03.002

Seidel, T., Schwindt, K., Rimmele, R., \& Prenzel, M. (2008). Konstruktivistische Überzeugungen von Lehrpersonen: Was bedeuten sie für den Unterricht? Zeitschrift für Erziehungswissenschaft, Sonderheft 9, 259-276. 
Seifried, J. (2010). Sichtweisen von Lehrkräften an kaufmännischen Schulen. Zeitschrift für Berufs- und Wirtschaftspädagogik, 106(1), 199-219.

Seung, E., Bryan, L. A., \& Butler, M. B. (2009). Improving Preservice Middle Grades Science Teachers' Understanding of the Nature of Science Using Three Instructional Approaches. Journal of Science Teacher Education, 20, 157-177. http://dx.doi.org/10.1007/s10972-009-9130-2

Smith, D. C., \& Neale, D. C. (1989). The Construction of Subject Matter Knowledge in Primary Science Teaching. Teaching \& Teacher Education, 5(1), 1-20.

Weinert, F. E. (2001). Concept of Competence: A Conceptual Clarification. In D. S. Rychen \& L. H. Salganik (Eds.), Defining and selecting key competencies (pp. 45-65). Ashland, OH: Hogrefe \& Huber Publishers.

Woolfolk Hoy, A., Davis, H., \& Pape, S. J. (2006). Teacher Knowledge and Beliefs. In P. A. Alexander \& P. H. Winne (Eds.), Handbook of Educational Psychology (pp. 715-737). Mahwah, N.J: Erlbaum.

Zeichner, K. M., \& Gore, J. M. (1990). Teacher Socialization. In W. R. Houston (Ed.), Handbook of research on teacher education (pp. 329-348). New York: Macmillan Publishing Company.

Zeichner, K. M., \& Tabachnick, B. R. (1981). Are the Effects of University Teacher Education 'Washed Out' by School Experience? Journal of Teacher Education, 32(3), 7-11.

Zeichner, K. M., \& Tabachnick, B. R. (1985). The Development of Teacher Perspectives: Social Strategies and Institutional Control in the Socialization of Beginning Teachers. Journal of Education for Teaching, 11(1), $1-25$.

\section{(cc) EY}

This work is licensed under a Creative Commons Attribution 3.0 License. 